\title{
A Taxonomic Study of the Larvae of the Genus Chrysomela Linnaeus (Coleoptera: Chrysomelidae: Chrysomelinae) from Korea
}

\author{
Hee Wook Cho ${ }^{1}$, Jinyoung Park ${ }^{2}$ and Jong Eun Lee $\mathrm{e}^{1, *}$ \\ 'Department of Biological Science, Andong National University, Andong 760-749, Korea \\ ${ }^{2}$ National Institute of Agricultural Science and Technology, RDA, Suwon 441-100, Korea
}

\begin{abstract}
Last instar larvae of Chrysomela cuprea Fabricius, 1775 and $C$. tremula Fabricius, 1787 are described in detail for the first time. A key to known larvae of Korean Chrysomela, their illustrations and host plants are also given.
\end{abstract}

Key words: Coleoptera, Chrysomelidae, Chrysomela, larva, taxonomy, Korea

\section{INTRODUCTION}

The genus Chrysomela Linnaeus, 1758, containing approximately thirty species of three subgenera, is distributed over all the zoogeographical regions except for Australian and Neotropical regions (Gressitt and Kimoto, 1963; Seeno and Wilcox, 1982; Gruev, 1994; Arnett et al., 2002; Warchalowski, 2003; Lopatin et al., 2004). Seven species were recorded in Korea (Lee and An, 2001), but we were unable to find and examine Chrysomela cyaneoviridis Gruev, 1994, C. lapponica Linnaeus, 1758 and C. salicivorax (Fairmaire, 1888) in South Korea.

Both larvae and adults of the genus Chrysomela are known as forest pests, feeding on the foliage of Salix and Populus. Host plants of four Korean species were reported by Lee and Cho (2006), and the immature stages and life history of C. populi Linnaeus, 1758 and C. vigintipunctata (Scopoli, 1763) were well studied by Kimoto (1962a, b), Kimoto and Takizawa (1994), Lee (1996) and Lee and Chung (1997). However, the larvae of C. cuprea and C. tremula have not been thoroughly described, except for the key and brief illustration provided by Medvedev and Zaitsev (1978).

In the present paper, detailed descriptions and illustrations of the larvae of C. cuprea and C. tremula are provided for the first time in Korea. Also, a key to known larvae of Korean Chrysomela is given.

\section{MATERIALS AND METHODS}

Materials used in the present study were obtained by rear-

*To whom correspondence should be addressed

Tel: 82-54-820-5618, Fax: 82-54-841-1627

E-mail: jelee@andong.ac.kr ing adults in the laboratory. The larvae were preserved in $70 \%$ ethyl alcohol, cleared in $10 \% \mathrm{KOH}$ solution for 30 minutes, rinsed in water, and dissected under a stereoscopic microscope (SZX12; Olympus, Japan). For morphological study of the minute structure, the parts were mounted on slides and observed through a compound microscope (SZ4045; Olympus). Slide mounting procedures were carried out according to LeSage (1984), the terminology follows Anderson (1947) and Kimoto (1962a). Abbreviations of $\mathrm{L}, \mathrm{S}$ and $\mathrm{M}$ in parentheses stand for long, short and micro seta, respectively. The materials used in this study are deposited in the Insect Collection of Andong National University.

\section{SYSTEMATIC ACCOUNTS}

Family Chrysomelidae Latreille, 1802

Subfamily Chrysomelinae Latreille, 1802

Genus Chrysomela Linnaeus, 1758

Diagnosis. Body large, length 10-17 mm in full grown larvae. Mandible five-toothed, with two setae. Defensive glands present on tubercle DL of meso- and metathorax and abdominal segments I-VII. Tubercles distinct, D-DL-EPa and EPp type on prothorax, D and DL type on meso- and metathorax and abdomen. ad1 absent. Tubercle D of abdominal segment VI fused, or rarely separated. All tubercles pigmented except for a part of prothoracic D-DL-EPa. Tarsus strongly curved with pointed tip, enlarged basally, with a seta.

Key to known larvae of Korean Chrysomela 1. Tubercle D of abdominal segment VI separated C. vigintipunctata 

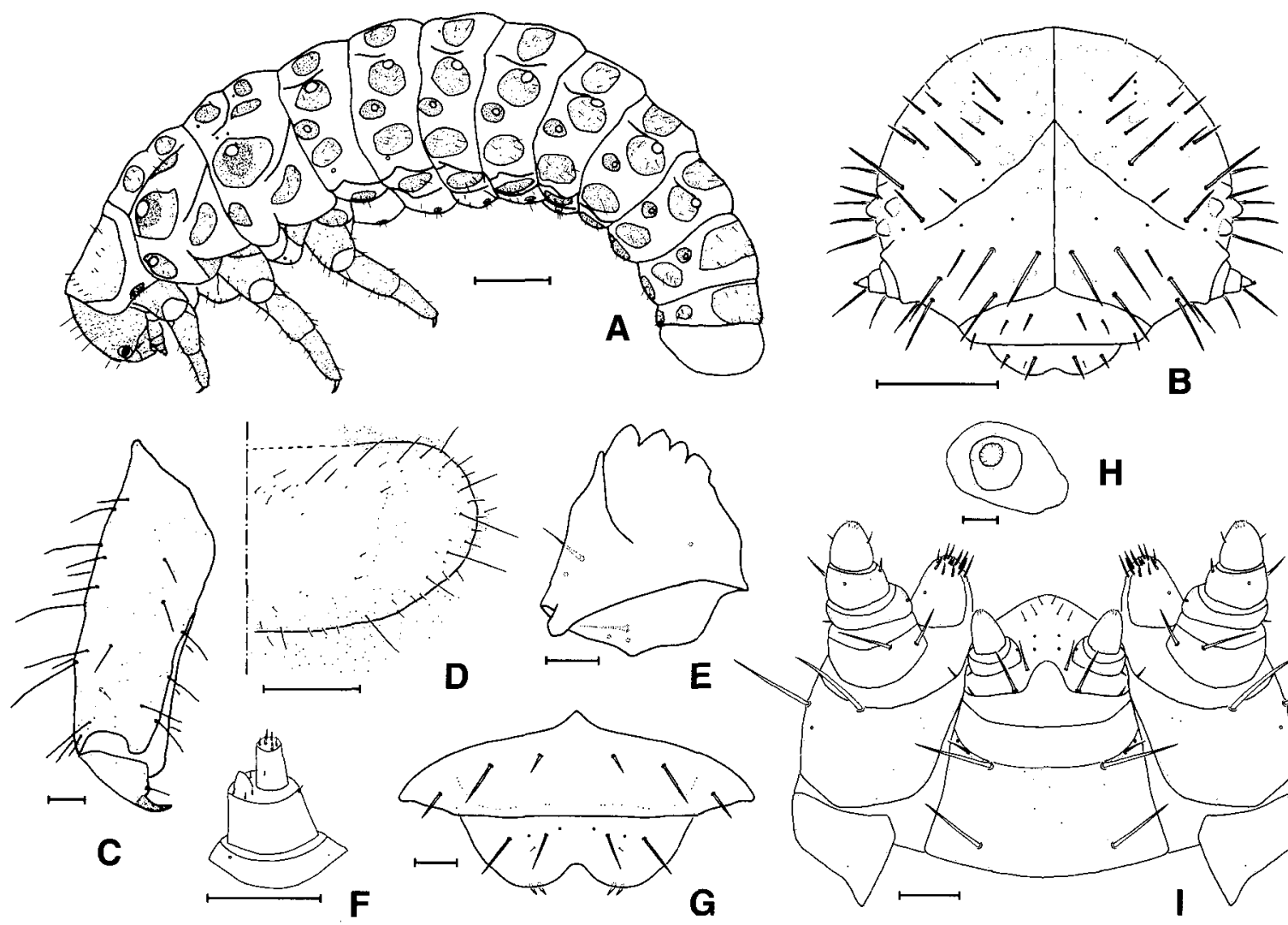

G

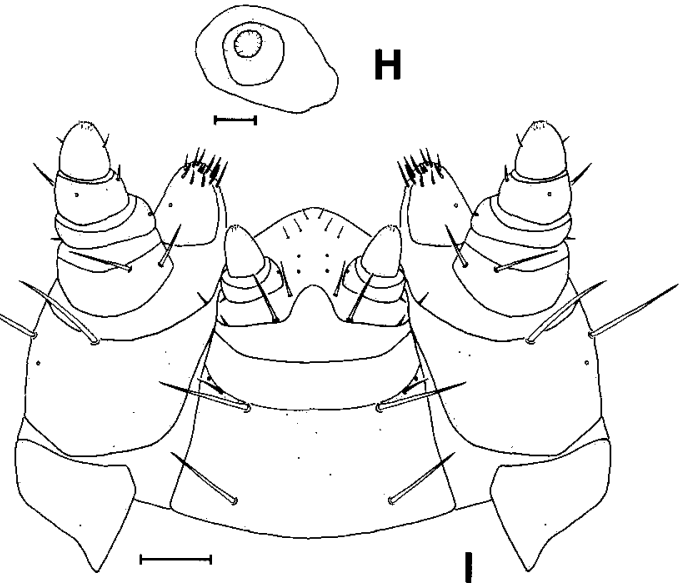

Fig. 1. Chrysomela cuprea Fabricius. A, Last instar larva (I.v.); B, Head (d.v.); C, Tibia (d.v.); D, Pronotum (d.v.); E, Mandible (b.v.); F, Antenna (d.v.); G, Clypeus and labrum (d.v.); H, Spiracle (d.v.); I, Lower mouth parts (v.v.). b.v.: buccal view; d.v.: dorsal view; I.v.: lateral view. Scale bars $=1.0 \mathrm{~mm}(A), 0.5 \mathrm{~mm}(B, D), 0.1 \mathrm{~mm}(C, E-I)$.

- Tubercle D of abdominal segment VI fused

2. Median region of prothoracic D-DL-EPa unpigmented

C. tremula

- Antero-median region of prothoracic D-DL-EPa unpigmented

3. Sternal region of meso- and metathorax with four to nine secondary tubercles

C. cuprea

- Sternal region of meso- and metathorax with or without one secondary tubercle C. populi

\section{Chrysomela cuprea Fabricius, 1775 (Figs. 1A-I, 3A)}

Material examined. 7 exs., Odae Mt., Pyeongchang-gun, Gangwon-do, 14 May 2005 (H.W. Cho); 3 exs., Odae Mt., Pyeongchang-gun, Gangwon-do, 31 May 2006 (H.W. Cho). Last instar larva. Body length $11.7 \mathrm{~mm}$, width $3.4 \mathrm{~mm}$, head width $1.5 \mathrm{~mm}(\mathrm{n}=4)$. Body yellowish white, head blackish brown and legs dark brown to brown. Tubercles on dorsal surface blackish brown except for antero-median region of prothoracic D-DL-EPa, on ventral surface pale brown and rather weak. Chitinous platelets on dorsal surface nearly absent, on ventral surface weak. Defensive glands present.

Head (Fig. 1B). Epicranium covered with obscure dark spots, with twenty-two pairs of setae. Frons with six pairs of setae. Six stemmata present on each side. Antenna (Fig. 1F) three-segmented. Clypeus (Fig. 1G) with three pairs of setae. Labrum notched at anterior margin, with three pairs of setae; epipharynx with two pairs of setae. Mandible (Fig. 1E) fivetoothed, with two setae. Maxillary palp (Fig. 1I) three-segmented; palpifer with two setae; stipes with three setae; cardo without seta; mala (fused galea and lacinia) with twelve setae. Labial palp two-segmented; prementum with six pairs of setae; postmentum with three pairs of setae.

Thorax (Figs. 1D, 3A). Dorsal and epipleural regions of prothorax with two tubercles D-DL-EPa (8-10L, 28-33S) and EPp (1L, 2-5S); pleural region with a tubercle P (2S); sternal region with a primaty tubercle ES-SS $(1 \mathrm{~L}, 1 \mathrm{~S})$ and two to four secondary tubercles. Dorsal region of meso- and metathorax with four tubercles $\mathrm{Da}(10 \mathrm{~S}, 4-5 \mathrm{M})$, Dpi (5S, $1 \mathrm{M})$, Dpe (1L, 5-7S), DL (1L, 12-15S); epipleural region with two tubercles EPa (6-9S) and EPp (1L, 12-14S); pleural region with a tubercle $P(2 S)$; sternal region with two pri- 


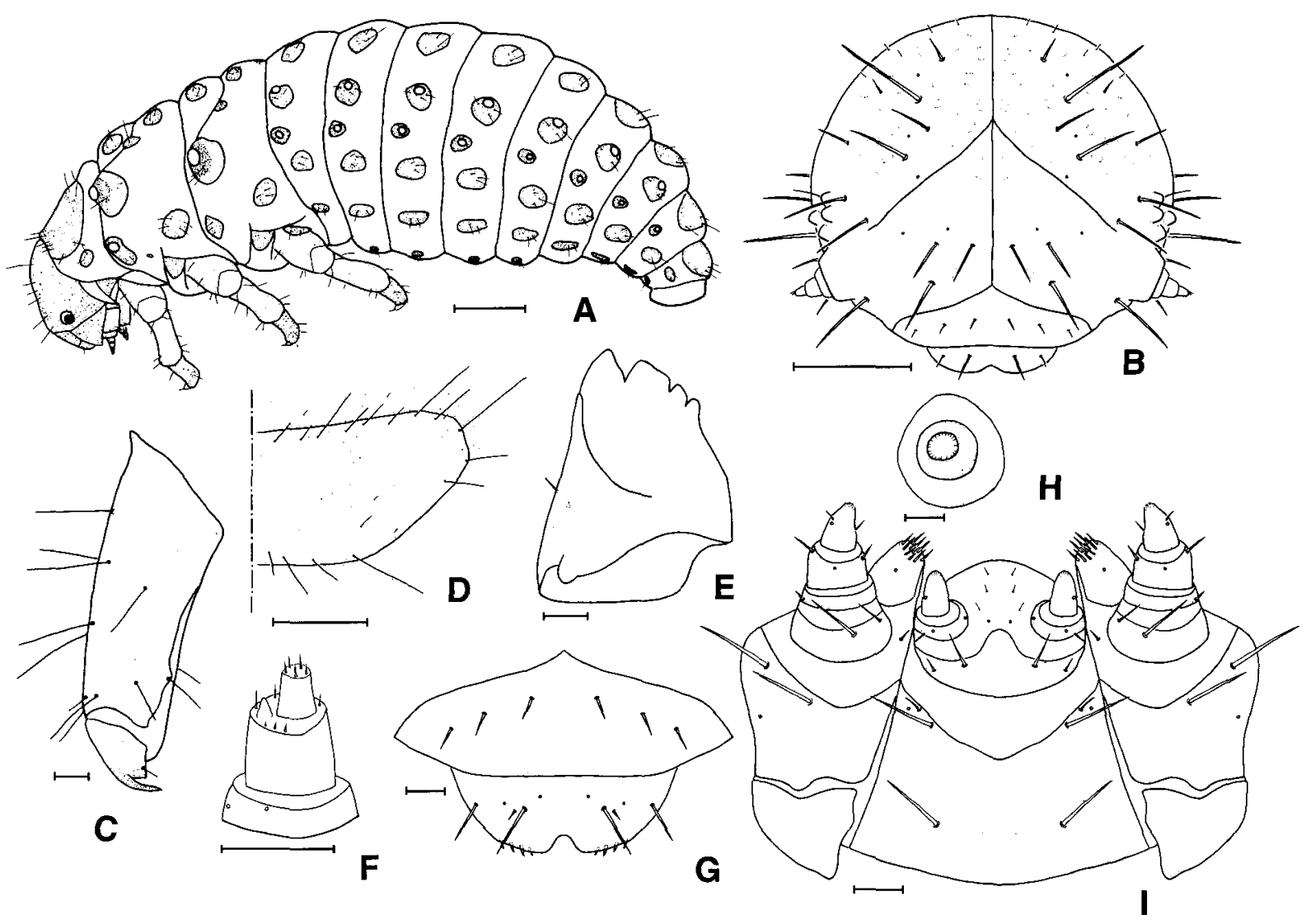

Fig. 2. Chrysomela tremula Fabricius. A, Last instar larva (I.v.); B, Head (d.v.); C, Tibia (d.v.); D, Pronotum (d.v.); E, Mandible (b.v.); F, Antenna (d.v.); G, Clypeus and labrum (d.v.); H, Spiracle (d.v.); I, Lower mouth parts (v.v.). b.v.: buccal view; d.v.: dorsal view; I.v.: lateral view. Scale bars $=1.0 \mathrm{~mm}(A), 0.5 \mathrm{~mm}(B, D), 0.1 \mathrm{~mm}(C, E-I)$.

mary tubercles SS (1S), ES (1L, 1S) and four to nine secondary tubercles. Mesothoracic spiracles annuliform, located on EPai. Tibia (Fig. 1C) with twenty-four setae; tarsus strongly curved with pointed tip, enlarged basally, with a seta.

Abdomen (Fig. 3A). Dorsal region with two tubercles D (13-14S) and DL (1L, 5-7S); epipleural region with a tubercle EP (1L, 11-12S); pleural region with a tubercle $\mathrm{P}(1 \mathrm{~L}, 4-$ $5 S$ ); sternal region with two primary tubercles PS-SS (2L, 3-6S), ES (1L), two secondary tubercles as1 (1S), as2 (1S). Sixth to seventh segments with tubercle D on both sides fused. Eighth to ninth segments with dorsal and dorso-lateral tubercles fused. Spiracles (Fig. 1H) present on segments I-VIII.

Diagnosis. The larva of this species is similar to that of $C$. populi, but can be distinguished by the smaller size, more than thirty setae on prothoracic D-DL-EPa and four to nine secondary tubercles on sternal region of meso- and metathorax.

Distribution. Korea, Japan, Mongolia, Russia and Europe.
Host Plants. Salix spp. and Populus maximowiczii Henry.

\section{Chrysomela tremula Fabricius, 1787 (Figs. 2A-I, 3B)}

Material examined. 30 exs., Kangwon National University, Chuncheon-si, Gangwon-do, 4 Aug 2004 (H.W. Cho); 20 exs., Cheongbok-ri, Yecheon-eup, Yecheon-gun, Gyeongsangbuk-do, 5 Sep 2006 (H.W. Cho and J.Y. Park).

Last instar larva. Body length $11.5 \mathrm{~mm}$, width $3.5 \mathrm{~mm}$, head width $1.6 \mathrm{~mm}(\mathrm{n}=10)$. Body yellowish white, head blackish brown and legs dark brown to brown. Tubercles on dorsal surface blackish brown except for median region of prothoracic D-DL-EPa, on ventral surface pale brown and rather weak. Chitinous platelets on dorsal surface weak, on ventral surface weak and largely absent. Defensive glands present.

Head (Fig. 2B). Epicranium covered with obscure dark spots, with nineteen pairs of setae. Frons with four pairs of setae. Six stemmata present on each side. Antenna (Fig. 2F) three-segmented. Clypeus (Fig. 2G) with three pairs of setae. Labrum notched at anterior margin, with three pairs of setae; 


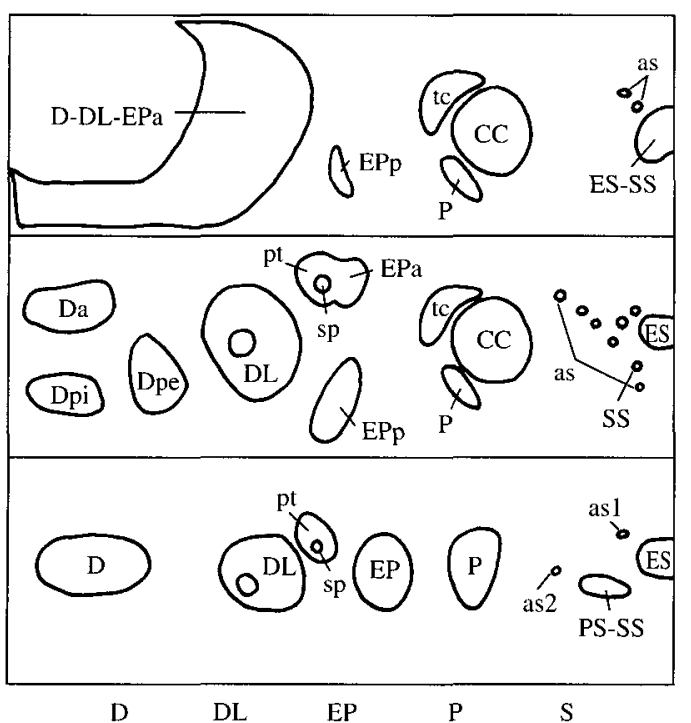

A

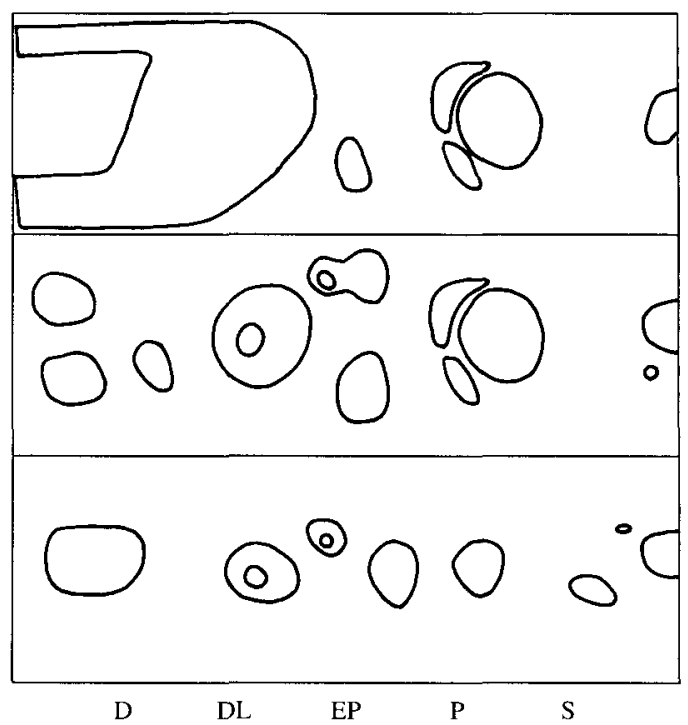

B

Fig. 3. Schematics of larval tubercle pattern. A, Chrysomela cuprea Fabricius; B, Chrysomela tremula Fabricius.

epipharynx with four pairs of setae. Mandible (Fig. 2E) five -toothed, with two setae. Maxillary palp (Fig. 2I) three-segmented; palpifer with two setae; stipes with three setae; cardo without seta; mala with eleven setae. Labial palp twosegmented; prementum with five pairs of setae; postmentum with three pairs of setae.

Thorax (Figs. 2D, 3B). Dorsal and epipleural regions of prothorax with two tubercles D-DL-EPa (14-18L, 4-8S) and $\operatorname{EPp}(1 \mathrm{~L}, 2-3 \mathrm{~S})$; pleural region with a tubercle $\mathrm{P}(2 \mathrm{~S})$; sternal region with a tubercle ES-SS (2S). Dorsal region of meso- and metathorax with four tubercles Da (2S, 2M), Dpi (2S), Dpe (1L, 2-4S), DL (1L, 3S, 6-8M); epipleural region with two tubercles $\mathrm{EPa}(1 \mathrm{~L}, 2-3 \mathrm{~S})$ and $\mathrm{EPp}(3 \mathrm{~L}, 2-4 \mathrm{~S})$; pleural region with a tubercle $\mathrm{P}(2 \mathrm{~S})$; sternal region with two primary tubercles SS (1S), ES (2L) and one secondary tubercle. Mesothoracic spiracles annuliform, located on EPai. Tibia (Fig. 2C) with twelve setae; tarsus strongly curved with pointed tip, enlarged basally, with a seta.

Abdomen (Fig. 3B). Dorsal region with two tubercles D $(1 \mathrm{~L}, 6 \mathrm{~S}, 1 \mathrm{M})$ and $\mathrm{DL}(1 \mathrm{~L}, 1 \mathrm{~S})$; epipleural region with a tubercle EP (1L, 4-5S); pleural region with a tubercle P (1L, $3 S$ ); sternal region with two primary tubercles PS-SS (3S), ES (1L), one secondary tubercle as I (1M). Sixth to seventh segments with tubercle D on both sides fused. Eighth to ninth segments with dorsal and dorso-lateral tubercles fused. Spiracles (Fig. 2H) present on segments I-VIII.

Diagnosis. The larva of this species is similar to that of $C$. vigintipunctata, but can be distinguished by the fused tubercle D of abdominal segment VI.
Distribution. Korea, Japan, China, Mongolia, Russia and Europe.

Host Plants. Salix spp., Populus tomentiglandulosa T. Lee and $P$. deltoides Marsh.

\section{ACKNOWLEDGEMENTS}

We thank to Dr. Hae-Chul Park (National Institute of Agricultural Science and Technology, Korea) for critically reading the manuscript. This work was supported by the Andong National University's Special Grant Program of 2006.

\section{REFERENCES}

Anderson, W.H., 1947. A terminology for the anatomical characters useful in the taxonomy of the weevil larvae. Proc. Ent. Soc. Wash., 49: 123-132.

Arnett, R.H., M.C. Thomas, P.E. Skelley and J.H. Frank, 2002. American beetles Vol. 2. Polyphaga: Scarabaeoidea through Curculionoidea. CRC Press, pp. 617-691.

Gressitt, J.L. and S. Kimoto, 1963. The Chrysomelidae (Coleopt.) of China and Korea II. Pac. Ins. Monogr., 1B: 3001026.

Gruev, B., 1994. New distributional data about some Leaf beetles in the Korea Peninsula and descriptions of four new species (Coleoptera, Chrysomelidae). Ins. Koreana, 11: 7584.

Kimoto, S., 1962a. A phylogenic consideration of Chrysomeli- 
nae based on immature stages of Japanese species (Coleoptera). J. Fac. Agric. Kyushu Univ., 12(2): 67-89.

Kimoto, S., 1962b. Descriptions of immature stages of Japanese Chrysomelinae belonging to the generic group Chrysomela (Coleoptera). J. Fac. Agric. Kyushu Univ., 12: 105118.

Kimoto, S. and H. Takizawa, 1994. Leaf beetles (Chrysomelidae) of Japan. Tokai Univ. Press, pp. 1-539.

Lee, J.E., 1996. Systematic study of Korean Chrysomelinae (Coleoptera: Chrysomelidae) by larval characters. Korean J. Entomol., 26(2): 125-134.

Lee, B.Y. and Y.J. Chung, 1997. Insect pests of Trees and Shrubs in Korea. Seong An Dang Publishing, Korea, pp. 10-13. (in Korean)

Lee, J.E. and S.L. An, 2001. Family Chrysomelidae. Economic Insects of Korea 14. Ins. Koreana Suppl. 21, pp. 1-231. (in Korean with English summary)

Lee, J.E. and H.W. Cho, 2006. Leaf beetles in the Crops (Coleoptera: Chrysomelidae). Economic Insects of Korea 27.
Ins. Koreana Suppl. 34, pp. 1-130. (in Korean with English summary)

LeSage, L., 1984. Immature stages of Canadian Neochlamisus Karren (Coleoptera: Chrysomelidae). Can. Entomol., 116: 383-409.

Lopatin, I.K., O.R. Aleksandrovich and A.S. Konstantinov, 2004. Check list of Leaf-Beetles (Coleotera, Chrysomelidae) of the Eastern Europe and Northern Asia. Olsztyn, pp. 114-115.

Medvedev, L.N. and Y.M. Zaitsev, 1978. Larvae of leaf beetles of Siberia and Far East. Nauka, Moscow, pp. 1-183. (in Russian)

Seeno, T.N. and J.A. Wilcox, 1982. Leaf beetles genera (Coleoptera: Chrysomelidae). Entomography, 1: 1-221.

Warchalowski, A., 2003. Chrysomelidae. The Leaf-beetles of Europe and The Mediterrnean Area. Warsaw, pp. 303-306.

Received March 13, 2007 Accepted April 24, 2007 